\title{
LONG-TERM RESULTS OF MITRAL-AORTIC VALVE OPERATIONS
}

Xavier M. Mueller, MD

Hendrik T. Tevaearai, MD

Frank Stumpe, MD

Adam P. Fischer, MD

Michel Hurni, MD

Patrick Ruchat, MD

Ludwig K. von Segesser, MD
Objective: We analyzed the long-term morbidity and mortality of our experience with combined mitral-aortic surgery, as well as their determinants. Methods: Among 2109 consecutive patients undergoing valve operations, 200 had mitral-aortic valve procedures with at least implantation of a mechanical prosthesis: 163 of $200(81.5 \%)$ patients had double valve replacement and 37 of $200(\mathbf{1 8 . 5 \%})$ had mitral valve repair and aortic valve replacement. All mechanical valves were bileaflet prostheses. Preoperatively, 171 of $200(85.5 \%)$ patients were in New York Heart Association class III-IV. Event-free survivals were determined by means of the Kaplan-Meier method and determinants of survivals with the Cox proportional hazards model $(p<0.05)$ entering 39 preoperative and perioperative factors. Follow-up was complete for $96 \%$ of the patients (192/200). Results: Overall survivals at 5,10 , and 15 years were $88.5 \% \pm 0.55 \%, 73.5 \% \pm 4 \%$, and $53.3 \%$ $\pm \mathbf{8 . 9 \%}$, and rates of freedom from valve-related mortality were $92.9 \% \pm$ $1.5 \%, 85.8 \% \pm 3.5 \%$, and $85.8 \% \pm 3.5 \%$. The rates of freedom from permanent valve-related impairment were $91.5 \% \pm 1.7 \%, 85.4 \% \pm 3.5 \%$, and $79.3 \% \pm 6.7 \%$, and those from all valve-related mortality and morbidity were $\mathbf{7 4 . 1 \%} \pm \mathbf{2 . 3 \%}, \mathbf{5 3 . 8 \%} \pm \mathbf{5 \%}$, and $\mathbf{4 9 \%} \pm \mathbf{5 . 6 \%}$. At last follow-up, $90 \%$ $(139 / 154)$ of the survivors were in New York Heart Association class I-II. Left ventricular ejection fraction less than $\mathbf{5 0 \%}$, age older than 70 years, and preoperative ventricular arrhythmias were independent risk factors for valve-related late deaths. Diabetes, ejection fraction less than $50 \%$, and coronary artery disease were independent determinants of all valve-related events. Conclusions: Functional results of survivors of combined mitralaortic surgery are excellent. However long-term valve-related morbidity and mortality are substantial. In the patient population studied, the predictors are determined by patient-related factors, mainly myocardial factors, but not by valve-related factors. (J Thorac Cardiovasc Surg 1998;115:1298-309)
$\mathrm{D}$ uring the past 15 years, bileaflet prostheses, especially the St. Jude Medical prostheses (St. Jude Medical, Inc., St. Paul, Minn.), have been the cardiac valve of choice at many centers and have represented a valuable alternative to other available mechanical and bioprosthetic devices. The results of bileaflet prosthesis with single valve surgery have been extensively reported. ${ }^{1}$ The late outcome $(\geq 10$

From the Clinic for Cardiovascular Surgery, CHUV (Centre Hospitalier Universitaire Vaudois), Lausanne, Switzerland.

Received for publication Oct. 21, 1997; revisions requested Dec. 8, 1997; revisions received Jan. 9, 1997; accepted for publication Jan. 9, 1998.

Address for reprints: X. Mueller, MD, Department of Cardiovascular Surgery, CHUV, CH-1011 Lausanne, Switzerland.

Copyright (C) 1998 by Mosby, Inc.

$0022-5223 / 98 \$ 5.00+0 \quad \mathbf{1 2 / 1 / 8 8 8 1 3}$ years) after combined surgery of the aortic and the mitral valves is less well known. Most authors have associated the results of their mitral-aortic operations with those of isolated aortic or mitral valve operations. $^{2-9}$ Few have focused critically on this subset. $^{10-12}$

This study reports the long-term results of our experience with simultaneous surgery of the aortic and mitral valve with the implantation of at least one bileaflet prosthetic valve, as well as the determinants of adverse events.

\section{Patients and methods}

Patient population. All the patients who underwent combined aortic and mitral valve operations with the implantation of at least one bileaflet prosthetic valve between March 1981, when we first used bileaflet prosthesis for a double valve replacement, and April 1996 were 
reviewed. Patients with concomitant coronary artery bypass operations and other valve procedures were included in the study. The study comprised 200 such patients among a total of 2109 patients having undergone valvular surgery during the same time period. The main clinical characteristics of the patient population are shown in Table I. The cause of valvular disease was rheumatic in 110 patients $(55 \%)$, degenerative in 42 patients $(21 \%)$, active endocarditis in 19 patients $(9.5 \%)$, congenital in 16 patients $(8 \%)$ and long-term complications of previous valve operations in 13 patients $(6.5 \%)$.

Surgical procedure. All the operations were performed with the patient supported by standard cardiopulmonary bypass, with moderate hemodilution and moderate hypothermia $\left(28^{\circ} \mathrm{C}\right)$. Cold crystalloid cardioplegia and topical pericardial cooling were used for myocardial protection. Valve implants were secured into position with six running 2-0 polypropylene sutures for the aortic valve and eight for the mitral valve. When used, mitral valve repair techniques were those described by Carpentier. ${ }^{13}$ Mitral valve repair was introduced in our institution in 1985 .

One hundred sixty-three patients $(81.5 \%)$ had double heart valve replacement with mechanical prostheses. Thirty-seven patients $(18.5 \%)$ had mitral valve repair and aortic valve replacement. All the mechanical valves were of the bileaflet type: 310 St. Jude Medical valves (171 aortic and 139 mitral), 34 CarboMedics valves (19 aortic and 15 mitral) (Sulzer Carbomedics Inc., Winterthur, Switzerland), and 19 ATS valves (10 aortic and 9 mitral) (Advancing The Standard Medical Inc., Minneapolis, Minn.). Associated procedures were performed in 38 patients (19\%): 22 tricuspid operations (11\%) (20 repairs and 2 bileaflet prostheses) and 18 coronary artery bypass grafts $(9 \%)$.

Postoperative anticoagulation. Anticoagulation therapy with continuous intravenous heparin $(10,000$ units in 24 hours) was started 12 hours after the operation. Oral anticoagulation with acenocoumarol was instituted 24 hours after the operation and heparin was continued until the target international normalized ratio was brought to a value of 3 to 4 . After hospital discharge, the general practitioner was responsible for anticoagulation control.

Follow-up. All the follow-up data were collected over a 2 -month period. Information was obtained by double phone interviews with all living patients and with either the family or general practitioner to increase the accuracy of the follow-up. Data for the deceased patients were collected from the family and the general practitioner. Contact was lost with eight patients. Follow-up was $96 \%$ complete with double interviews in all survivors. This represents 1144 patient-years with a mean of 5.7 years per patient, a minimum of 6 months, and a maximum of 15.2 years. All traced patients were evaluated for valve-related complications and New York Heart Association class at the time of follow-up and reoperation. Long-term follow-up echocardiographic data were obtainable in 120 of the 164 survivors $(73 \%)$ who had routine echocardiographic examinations.

Definitions. Complications were defined in accordance with the published guidelines for reporting valve-related morbidity and mortality after cardiac valvular operation. ${ }^{14}$ They included structural deterioration, nonstructural dys-
Table I. Clinical characteristics of the patient population

\begin{tabular}{lcrc}
\hline & Mean \pm & \multicolumn{2}{c}{ Patients } \\
\cline { 4 - 4 } & $S D$ (range) & No. & $\%$ \\
\hline Age (yr) & $56.2 \pm 13.6$ & & \\
& $(16-81)$ & & \\
Female & & 105 & 52.5 \\
NYHA functional class & & \\
I & & 1 & 0.5 \\
II & 33 & 16.5 \\
III & 66 & 33 \\
IV & 100 & 50 \\
Arrhythmias & & & \\
AF & 114 & 57 \\
Ventricular arrhythmias & 9 & 4.5 \\
CAD & 17 & 8.5 \\
Diabetes & & 12 & 6 \\
Creatinine $\geq 120 \mu$ mol/L & & 36 & 18 \\
Alcoholism & 11 & 5.5 \\
Urgent operation & 25 & 12.5 \\
\hline Atial & & &
\end{tabular}

$A F$, Atrial fibrillation; $C A D$, coronary artery disease; NYHA class, New York Heart Association class; $\pm \mathrm{SD}=1$ standard deviation.

function, valve thrombosis, embolism, bleeding event, prosthetic valve endocarditis, reoperation, valve-related mortality, permanent valve-related impairment, and all valve-related morbidity and mortality. To detect as many transient ischemic accidents as possible, we asked the patients whether they had had blurred or double vision, difficulty in speaking or moving a limb, facial asymmetry, loss of sensitivity, sudden gait disturbance, dizziness, or transient loss of memory. Sudden death was defined as a nonaccidental witnessed or unwitnessed death of a person for whom time of death was unexpected and mode of death was unexplained. Because of the controversy about the justification in considering sudden death as part of a valve-related death, ${ }^{15}$ the results for valve-related death and combined valve-related mortality and morbidity are presented both including and excluding cases of sudden death.

Statistical analysis. All data were entered into a spreadsheet (Microsoft Excel 4, Microsoft Corporation, Redmond, Wash.) and analyzed with StatView 4.5 statistical software for Macintosh (Abacus Concepts Inc., Berkeley, Calif.). The different late valve-related events were expressed in linearized form (percent per patientyear) for which all events were considered. So that the long-term results could be described in accordance with the guidelines,${ }^{14}$ actuarial curves for mortality and complications were obtained by the Kaplan-Meier method and reported with the standard error of the estimate. For this analysis, only the first event of each type of complication was considered. Univariate comparisons of subgroups were made with the log-rank test. Variables with a $p<$ 0.05 were entered into the Cox's proportional hazard model to identify independent prognostic factors. When some covariates were highly correlated, we included the most significant one. Results of the multivariate analysis are given with estimates of the $\beta$ coefficient and as odds 


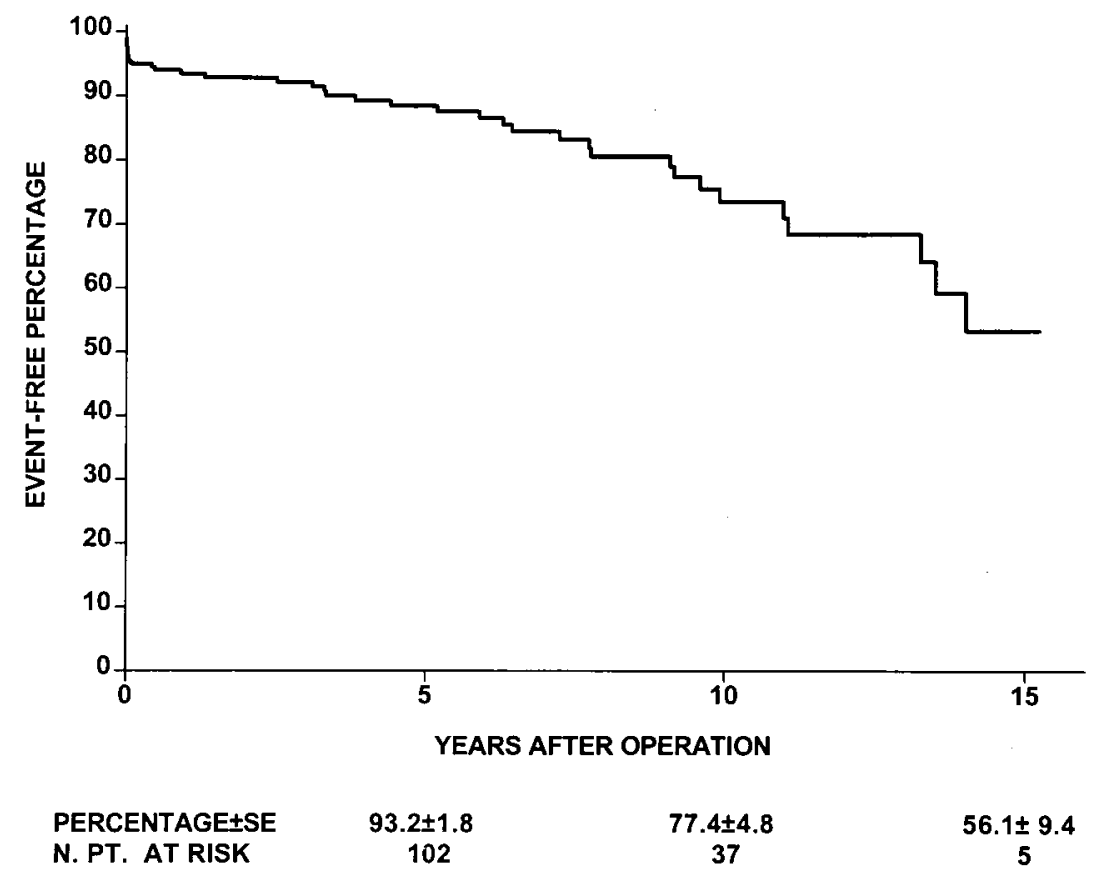

Fig. 1. Actuarial overall survival. $S E$, Standard error of the estimate; N. PT., number of patients.

ratio (95\% confidence interval), with the significance level $p$ value for each variable. The events tested were embolisms, overall mortality, valve-related mortality, sudden death, and overall valve-related events. Bleeding events and prosthetic valve thromboses were not tested because they are most likely due to excessive or insufficient oral anticoagulation, and blood coagulation tests were not available at the time of the event in most patients. Hemolysis and nonstructural valve failure were not analyzed because they were not formally screened. Endocarditis was not tested because too few events occurred. The list of the 39 screened variables is given in Appendix Table I.

\section{Results}

Survival. Ten patients died within 1 month of the operation, yielding a 30-day mortality of 5\%. Eight patients died of a cardiac nonvalvular cause, six of them of pump failure. One death was considered valve-related: a myocardial infarction on the third postoperative day, without coronary artery disease on catheterization. One death was noncardiac: a ruptured intracranial mycotic aneurysm. There were 26 late deaths, for a linearized incidence of $2.3 \% / \mathrm{pt}$-yr. Fourteen deaths $(54 \%)$ were valverelated, 8 deaths $(31 \%)$ were cardiac non-valverelated, and four deaths (15\%) were noncardiac. Actuarial survivals at 5, 10, and 15 years are depicted in Fig. 1.

\section{Valve-related complications}

Structural deterioration. Structural deterioration did not occur in any patient in this study.

Nonstructural dysfunction. Nonstructural dysfunction occurred in two cases. One patient required a second aortic valve replacement because of a pannus ingrowth. One patient with an important aortic paravalvular dehiscence refused a reoperation and is still alive at 5 years. Eight symptom-free patients had incidental minor paravalvular leaks discovered by echocardiography, and these were not considered to be complications. All the paravalvular leaks were on the aortic valve. The linearized rate for nonstructural dysfunction was $0.2 \% / \mathrm{pt}-\mathrm{yr}$, and the 5-, 10-, and 15-year actuarial event-free rates were $99.3 \% \pm$ $0.7 \%, 97.7 \% \pm 1.7 \%$, and $97.7 \% \pm 1.7 \%$.

Thromboembolism. Valve thrombosis occurred in two patients. One patient died shortly after her admission in a comatose state. The autopsy showed thrombosis of both mitral and aortic prosthetic valves with massive cerebral embolism. The other patient with poor compliance had thrombosis of a tricuspid prosthetic valve and underwent successful thrombolysis. Both patients were receiving inadequate anticoagulation with a decreased prothrombin time ratio (almost 1). The linearized rate was $0.2 \%$ / pt-yr and the 5-, 10-, and 15-year actuarial event-free 


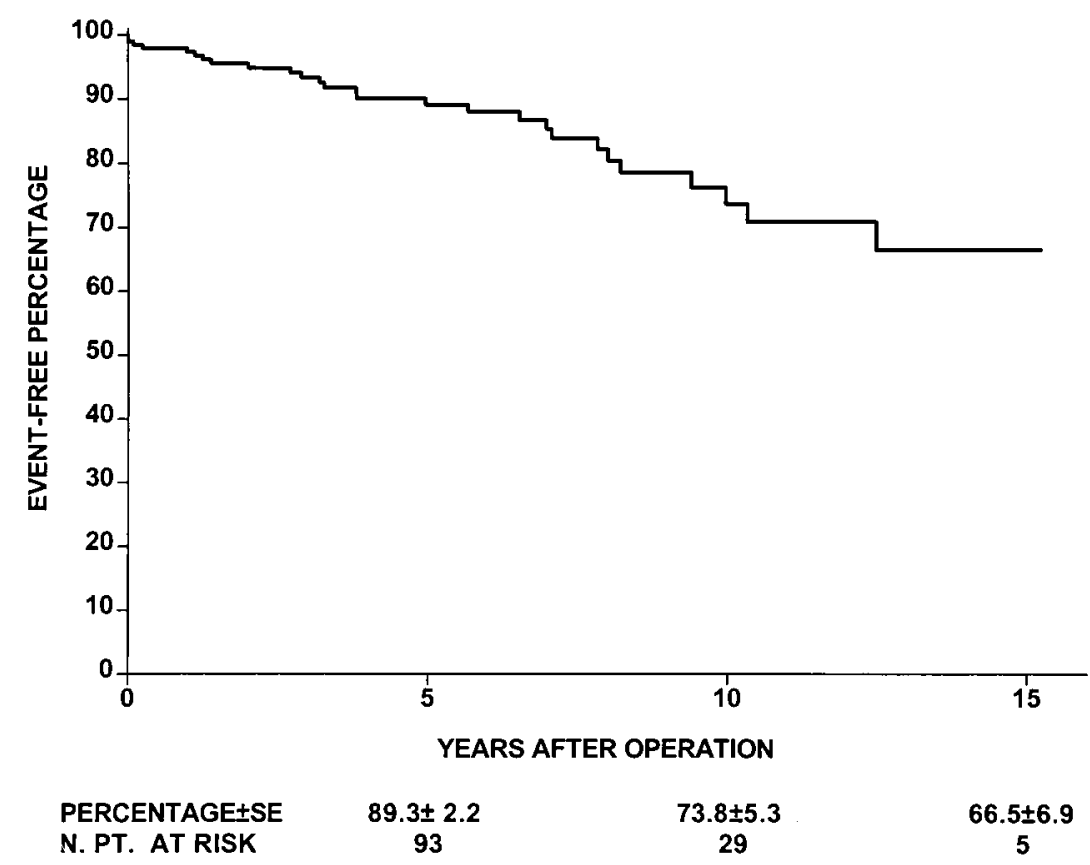

Fig. 2. Actuarial freedom from embolism. SE, Standard error of the estimate; N. PT., number of patients.

rates were $99.1 \% \pm 0.8 \%, 99.1 \% \pm 0.8 \%$, and $92.9 \% \pm 6 \%$.

Thirty embolisms were documented in 25 patients, for a linearized rate of $2.6 \% / \mathrm{pt}-\mathrm{yr}$. Five patients had an ischemic stroke, one of which was fatal. Twelve patients had transient ischemic attacks. Five patients had repeated cerebral ischemic events: two without sequel, two with persistent neurologic deficit, and one fatal. That patient died of cerebral infarctions because anticoagulation had to be leveled off owing to severe hemorrhaging after maxillary sinus drainage. Systemic embolism was recorded in three patients: two myocardial infarctions and one occlusion of a peripheral artery to a limb. Both myocardial infarctions, occurring on the third postoperative day and 1 year after the operation, respectively, were considered valve-related because preoperative angiography did not show any sign of coronary artery disease and no other reason such as myxoma or atherosclerosis of the ascending aorta could be involved. The frequency of valve-related impairment and death was $33 \%(10 / 30)$ and $10 \%$ (3/30), respectively. The 5-, 10-, and 15-year actuarial embolism-free rates are shown in Fig. 2.

Table II shows variables found to be significant in univariate and multivariate analysis of embolism. Notably, mitral valve plasty associated with aortic valve replacement did not result in significantly less embolism than double heart valve replacement. The actuarial event-free rates at 5 and 10 years were $96 \% \pm 3.9 \%$ and $82.3 \% \pm 13.1 \%$ for patients with mitral valve plasty versus $88.9 \% \pm 3 \%$ and $72.7 \% \pm$ $5.7 \%$ for patients with mitral valve replacement $(p=$ $0.176)$.

Bleeding events. A total of 30 bleeding events occurred in 27 patients. Two patients had intracranial hemorrhage, and both incurred permanent deficits. Twenty-five patients had 27 extracranial hemorrhages, and two of them died. The linearized rate for bleeding events was 2.6\%/pt-yr, and the 5-, 10-, and 15-year actuarial event-free rates are depicted in Fig. 3. The incidences of valve-related impairment and death were $13 \%(4 / 30)$ and $10 \%(3 / 30)$, respectively.

Prosthetic valve endocarditis. No cases of early prosthetic valve endocarditis developed, but late endocarditis developed in two patients. Both had double valve replacement with bileaflet mechanical prostheses. One patient underwent a sigmoidectomy 48 months after heart valve surgery because of volvulus and died 20 days after the operation of a Candida sepsis. Postmortem examination showed vegetations on both prosthetic valves and a massive cerebral infarct. The other patient presented 2 years after heart valve replacement with bronchopneumonia and left-sided cardiac failure with a moderate 
Table II. Risk factors for embolism, overall mortality, valve-related death, sudden death, and all valve-related events

\begin{tabular}{|c|c|c|c|c|c|c|}
\hline \multirow[b]{2}{*}{ Event } & \multirow[b]{2}{*}{ Variables } & \multirow{2}{*}{$\begin{array}{c}\text { Univariate analysis } \\
\text { by log-rank test } \\
p \text { Value }\end{array}$} & \multicolumn{4}{|c|}{$\begin{array}{l}\text { Cox's proportional hazard model } \\
\text { (independent risk factors) }\end{array}$} \\
\hline & & & $\beta$ & $O R$ & $95 \% C I$ & $p$ Value \\
\hline \multirow[t]{2}{*}{ Embolism } & Diabetes & 0.001 & 1.741 & 5.7 & $1.8-17.4$ & 0.002 \\
\hline & Associated CAD & 0.011 & 1.442 & 4.2 & $1.4-12.9$ & 0.015 \\
\hline \multirow[t]{9}{*}{ All deaths } & Age $>70 \mathrm{yr}$ & 0.001 & 1.285 & 3.6 & $1.2-10.9$ & 0.022 \\
\hline & LVEF $<50 \%$ & $<0.001$ & 1.009 & 2.7 & $1.1-6.6$ & 0.023 \\
\hline & Ventricular arrhythmias & 0.007 & & & & \\
\hline & Urgent operation & $<0.001$ & & & & \\
\hline & Diabetes & 0.002 & & & & \\
\hline & Creatinine $\geq 120 \mathrm{umol} / \mathrm{L}$ & 0.004 & & & & \\
\hline & Associated CAD & 0.009 & & & & \\
\hline & $\mathrm{RAP} \geq 8 \mathrm{~mm} \mathrm{Hg}$ & 0.011 & & & & \\
\hline & Cardiac index $\leq 2.5 \mathrm{~L} / \mathrm{min}$ & $0.048^{*}$ & & & & \\
\hline \multirow[t]{5}{*}{ Valve-related death including sudden death } & LVEF $<50 \%$ & $<0.001$ & 2.171 & 8.7 & $2.8-27.4$ & $<0.001$ \\
\hline & Age $>70 \mathrm{yr}$ & 0.005 & 2.058 & 7.8 & $1.9-33$ & 0.005 \\
\hline & Ventricular arrhythmias & 0.002 & 2.251 & 9.5 & $1.4-62.5$ & 0.019 \\
\hline & Urgent operation & 0.02 & & & & \\
\hline & Associated CAD & 0.001 & & & & \\
\hline \multirow[t]{2}{*}{ Valve-related death without sudden death } & LVEF $<50 \%$ & 0.01 & & & & \\
\hline & Associated CAD & 0.023 & & & & \\
\hline \multirow{2}{*}{ Sudden death } & Ventricular arrhythmias & 0.004 & & & & \\
\hline & NYHA class IV & 0.02 & & & & \\
\hline \multirow[t]{4}{*}{ All valve-related events } & Diabetes & 0.008 & 1.069 & 2.9 & $1.3-6.5$ & 0.009 \\
\hline & $\mathrm{LVEF}<50 \%$ & 0.016 & 0.745 & 2.1 & $1.1-3.9$ & 0.016 \\
\hline & Associated CAD & $<0.001$ & 0.795 & 2.2 & $1-4.7$ & 0.038 \\
\hline & Age $>70 \mathrm{yr}$ & 0.01 & & & & \\
\hline
\end{tabular}

$O R$, Odds ratio; $C I$, confidence interval; $C A D$, coronary artery disease; $L V E F$, left ventricular ejection fraction; $R A P$, right atrial pressure; $N Y H A$, New York Heart Association.

*Reason for excluding variables from Cox's model is given in the paragraph on statistics.

mitral paravalvular leak. Although blood cultures were not positive, the diagnosis was endocarditis inasmuch as echocardiograms taken at 6 months and 1 year showed no leak. The patient finally underwent closure of the increasing leak after a 6-week course of antibiotics. There was no sign of technical failure during the operation. The linearized rate for prosthetic valve endocarditis was $0.2 \% / \mathrm{pt}-\mathrm{yr}$ and the 5- and 15-year actuarial event-free rates were both $98.5 \% \pm 1 \%$.

\section{Valve-related consequences}

Reoperation. Two patients required reoperation involving the implanted valves. The first patient had a second aortic valve replacement because of pannus ingrowth, and the second had closure of an increasing endocarditic paravalvular leak. The linearized-rate for reoperation was $0.2 \% / \mathrm{pt}$-yr and the 5-, 10-, and 15 -year actuarial event-free rates were $99.3 \% \pm 0.7 \%, 97.7 \%$ $\pm 1.7 \%$, and $97.7 \% \pm 1.7 \%$, respectively.

Valve-related mortality. The 14 valve-related deaths included eight unexpected sudden deaths, two bleeding events, two cerebral embolisms, one case of prosthetic valve thrombosis, and one case of fungal endocarditis. The cause of death in six of seven $(86 \%)$ patients with established etiology was a thromboembolic or a bleeding event. The linearized rates for valve-related mortality were $1.2 \% / \mathrm{pt}$-yr and $0.5 \% / \mathrm{pt}$-yr when sudden deaths are excluded. The respective actuarial event-free rates at 5,10 , and 15 years with and without sudden deaths are shown in Fig. 4.

Table II shows variables found to be significant in univariate and multivariate analysis of valve-related mortality and sudden deaths. Here again, mitral valve plasty associated with aortic valve replacement did not result in a significantly lower incidence of valve-related death than double heart valve replacement. The actuarial event-free rates at 5 and 10 years were $88.2 \% \pm 5.6 \%$ and $82.3 \% \pm 7.7 \%$ for patients with mitral valve plasty versus $88.7 \% \pm$ $2.7 \%$ and $73.4 \% \pm 5 \%$ for patients with mitral valve replacement $(p=0.872)$.

Permanent valve-related impairment. Overall, 18 patients had 19 valve-related events with subsequent 


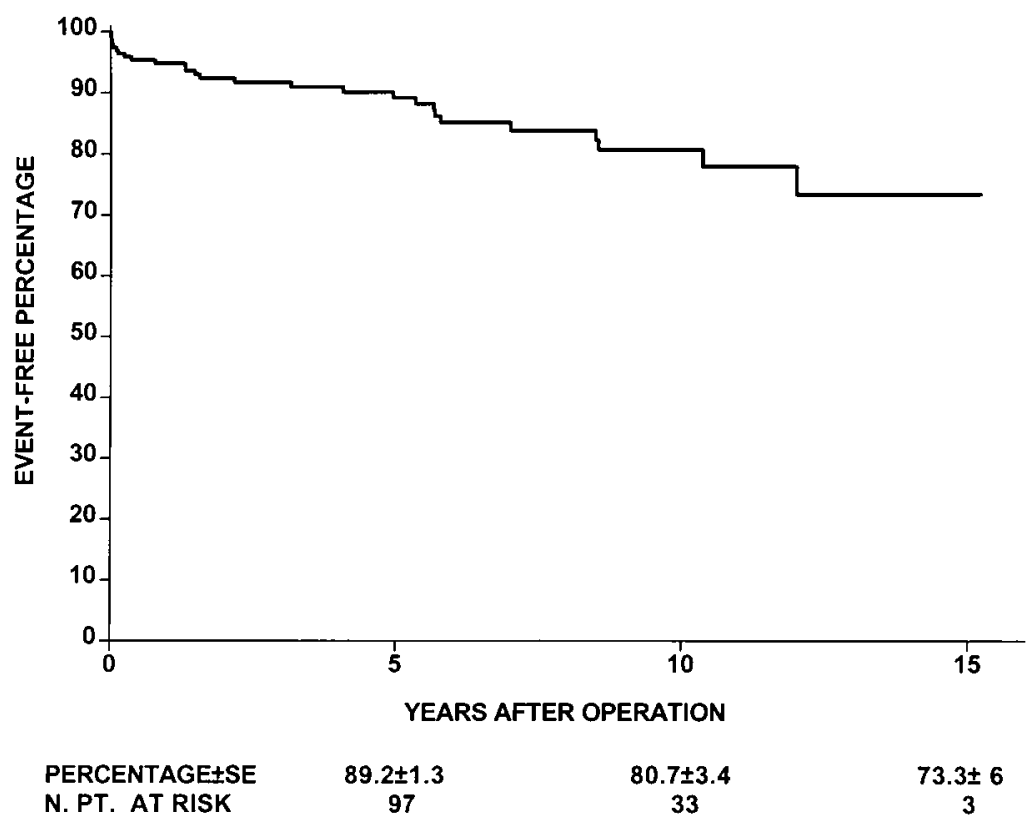

Fig. 3. Actuarial freedom from bleeding event. $S E$, Standard error of the estimate; $N$. PT., number of patients.

permanent functional deficit. These events included nonstructural dysfunction $(n=1)$, valve thrombosis $(n=2)$, embolic episodes $(n=10)$, bleeding events $(n=4)$, and endocarditis $(n=2)$. The linearized rate for permanent physical impairment was $1.7 \% / \mathrm{pt}-\mathrm{yr}$ and the 5-, 10-, and 15-year actuarial event-free rates are depicted in Fig. 5. A thromboembolic or bleeding event was the cause of 16 of $19(89 \%)$ permanent valverelated impairments.

All valve-related morbidity and mortality. All valverelated morbidity and mortality included 85 events in 62 patients, or a linearized rate of $7.4 \% / \mathrm{pt}-\mathrm{yr}$. When sudden deaths were excluded, there were 77 events in 54 patients, for a linearized rate of $6.7 \%$ / pt-yr. The 5-, 10-, and 15-year actuarial valve-related event-free rates with and without sudden death are shown in Fig. 6. Thromboembolism or bleeding was the cause of 60 of $77(78 \%)$ events.

Clinical condition. Comparison of New York Heart Association functional class before operation and by the latest date of follow-up in the 164 long-term survivors showed that $133(81 \%)$ of the survivors were in class III or IV before the operation, and at follow-up 145 (88\%) of the survivors were in functional class I or II. One hundred forty-three patients $(87 \%)$ had had improvement in their functional class by at least one stage at the time of follow-up.

\section{Discussion}

Operative risk of patient candidates for multivalvular operations has already been shown to be no longer substantially higher than that in patients with isolated valve replacement. ${ }^{16}$ However, studies focusing on the long-term results of this operation in the bileaflet prosthesis area have included no more than 100 patients, and the highest total follow-up was $309 \% /$ pt-yr. $^{10-12}$ The present study provides the long-term results of 200 patients operated on over a period of 15 years with a total follow-up of 1144 patient-years.

The linearized and actuarial event-free rates for embolism are in accordance with the findings of the literature. Table III presents the range of linearized rate of valve-related events associated with double valve surgery in 11 studies on bileaflet prostheses. Eight of these studies have reported the results of double valve surgery together with those of single valve surgery. When one considers the overall linearized rate for embolism in the latter studies, ranging from $0.5 \%$ to $3.5 \%$, our $2.6 \%$ still compares favorably. This confirms the low thrombogenesis of bileaflet valves, even in the scenario of double heart valve surgery. This statement is moderated by two considerations. First, most emboli are cerebral and because the brain receives only $14 \%$ of the total cardiac output, this is probably an underestimation of the true embolic incidence. Second, Horstkotte 


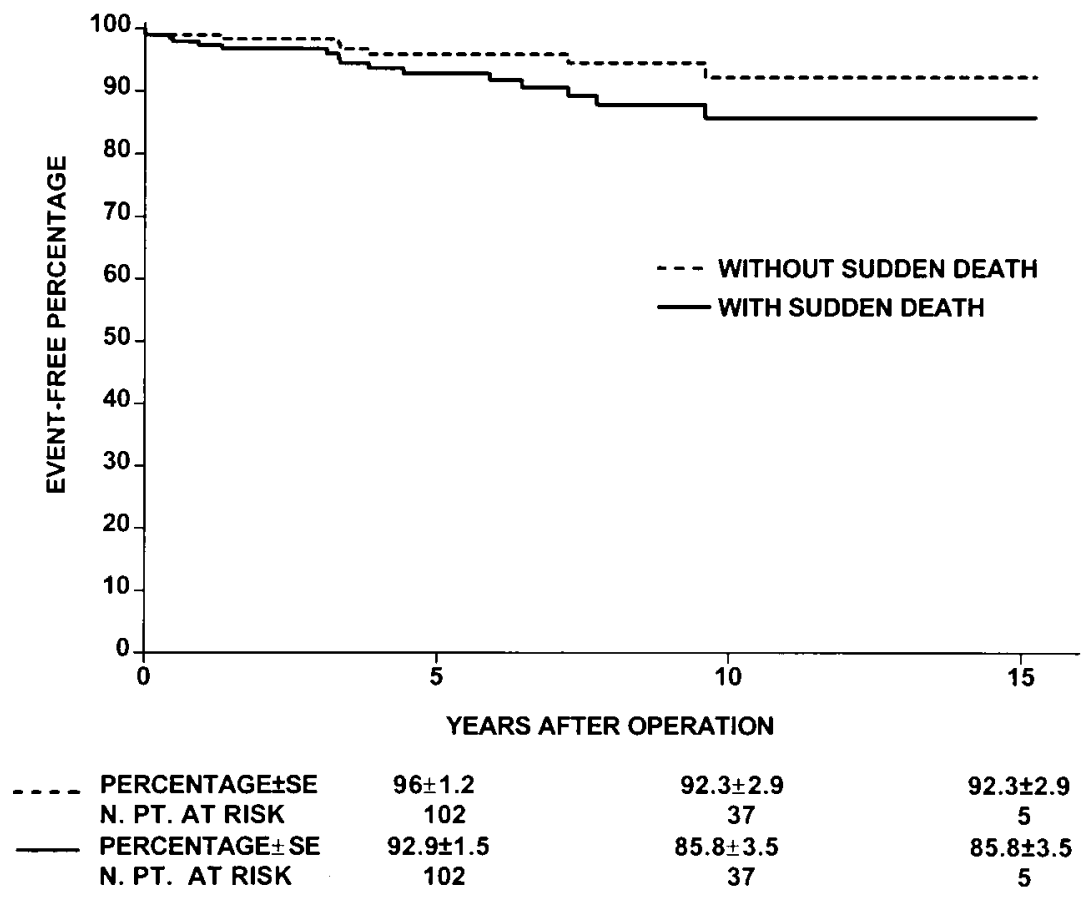

Fig. 4. Actuarial freedom from valve-related death with sudden death being included or excluded from valve-related death. SE, Standard error of the estimate; N. PT., number of patients.

and associates ${ }^{17}$ performed the only prospective long-term study of patients with St. Jude Medical prostheses using extremely conservative criteria for defining thromboembolism and bleeding complications to identify all possible complications irrespective of the severity of the event. They found an unexpected linearized rate of $5.3 \% / \mathrm{pt}$-yr of thromboembolism with double heart valve replacement. This indicates that the rates in retrospective studies are probably underestimated. On the other hand, results of multivariate analysis showed diabetes and associated coronary artery disease as independent risk factors for emboli. This suggests that emboli not linked with heart valves must exist, because both risk factors can be considered surrogates for atherosclerosis, a systemic disease also involving the precerebral arteries. Moreover, none of the valve-related risk factors were found to be significant, even on univariate analysis. In particular, patients with mitral valve plasty and aortic valve replacement did not fare significantly better than patients with double heart valve replacements.

Bleeding together with embolism were the most frequent valve-related complications. Inadequate anticoagulation has been recognized to be the main reason for their occurrence. ${ }^{7}$ Our linearized incidence is in the range of those reported in the literature (Table III); however, as for embolism this range is wide. The most likely explanation lies in the method of selection of bleeding events. According to the guidelines, ${ }^{14}$ we included any episode of internal or external bleeding that causes death, stroke, precipitates surgery or hospitalization, or requires transfusion. Therefore, in cataloging all the events that required a hospitalization, we also included benign events treated on an outpatient basis. This feature also explains the non-neurologic nature of most bleeding events. The remark concerning the weakness of retrospective study for registering embolism is also valid for bleeding events, inasmuch as Horstkotte and colleagues ${ }^{17}$ found, prospectively, a linearized incidence of hemorrhage of $6.1 \% / \mathrm{pt}-\mathrm{yr}$ in patients with double valve replacement.

Our experience with valve thromboses supports the findings of other series, including single valve replacement ${ }^{3,7}$ : it is a life-threatening complication, with a $50 \%$ mortality rate, and is due to inadequate anticoagulation. Notably, we had only two cases of late endocarditis with a linearized incidence of $0.2 \% / \mathrm{pt}-\mathrm{yr}$. None of the cases of endocarditis occurred in the group of patients with active endocarditis as a surgical indication. This suggests that a higher quantity of prosthetic material does not mean a higher risk of 


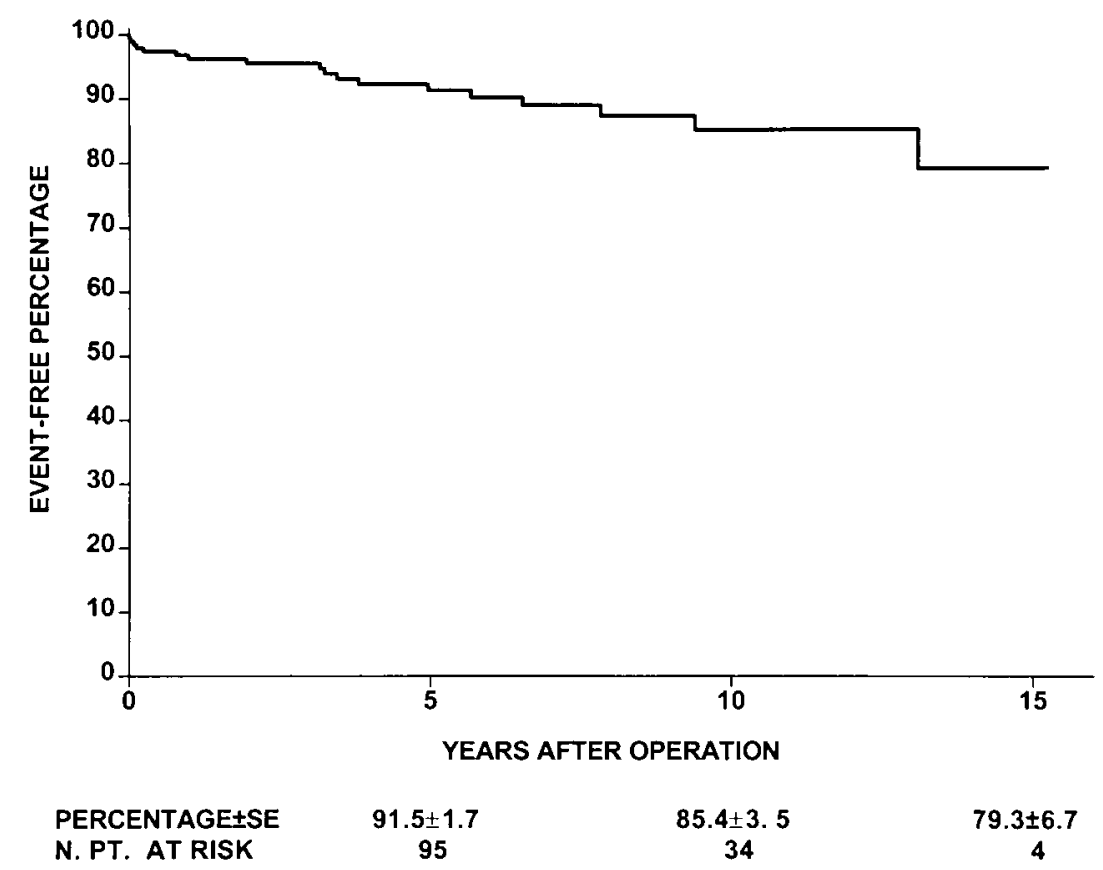

Fig. 5. Actuarial freedom from permanent valve-related impairment. $S E$, Standard error of the estimate; N. PT., number of patients.

infectious complications. Structural deterioration resulting in mechanical failure of the prosthesis did not occur. The review of the literature of Orsinelli and colleagues $^{18}$ reported six isolated cases of leaflet embolization and one case of leaflet fracture.

Because we perform valve implantation with running sutures, we wondered whether this technique would account for a higher rate of periprosthetic leak. We had only one patient with significant paravalvular leak. Incidental minor leak found at routine echocardiography was recorded in eight patients among 120 survivors (6.7\%) who underwent routine echocardiography. Some authors found a predominance of leakage in the mitral position. ${ }^{6,19}$ We found it exclusively in the aortic position. This could be due to the better visualization of the aortic valve on transthoracic echocardiography and the strain on the supporting structure of this valve in relation to the high pressure gradient.

Parallel to the findings of the literature, ${ }^{6,7,10,11,20}$ thromboembolism and bleeding events are still the most frequent and the most dangerous valve-related complications in terms of permanent valve-related event and survival: $74 \%(16 / 19)$ of valve-related impairments and $86 \%(6 / 7)$ of valve-related deaths with an established cause were due to a thromboembolic or bleeding event. These results highlight the hazards and limitations of anticoagulation in patients with mechanical prostheses and underline the fact that, although bileaflet prostheses compare most favorably with other substitute valves, the ideal valve has yet to been found. The inverse relationship between the incidence of thromboembolism and bleeding events has been previously recognized. ${ }^{21}$ The similar incidence of embolic and bleeding events would suggest that our level of anticoagulation is an adequate balance between excessive and insufficient anticoagulation in double heart valve surgery. Recently, however, some authors ${ }^{22}$ have suggested that a low international normalized ratio caused only a marginal increase in the rate of embolism but a highly significant decrease in the rate of bleeding. No large-scale results on double heart valve surgery have so far been reported, and guidelines for anticoagulation in double heart valve surgery are still lacking. ${ }^{23}$

The actuarial survival of patients free of valverelated mortality at 10 years is comparable with those of Smith, ${ }^{8}$ De Luca, ${ }^{9}$ and their coworkers for St. Jude Medical and CarboMedics valves, respectively. Risk factors associated with valve-related mortality by multivariate and by univariate analysis are all patient-related factors. Significant determinants include left ventricular ejection fraction less 


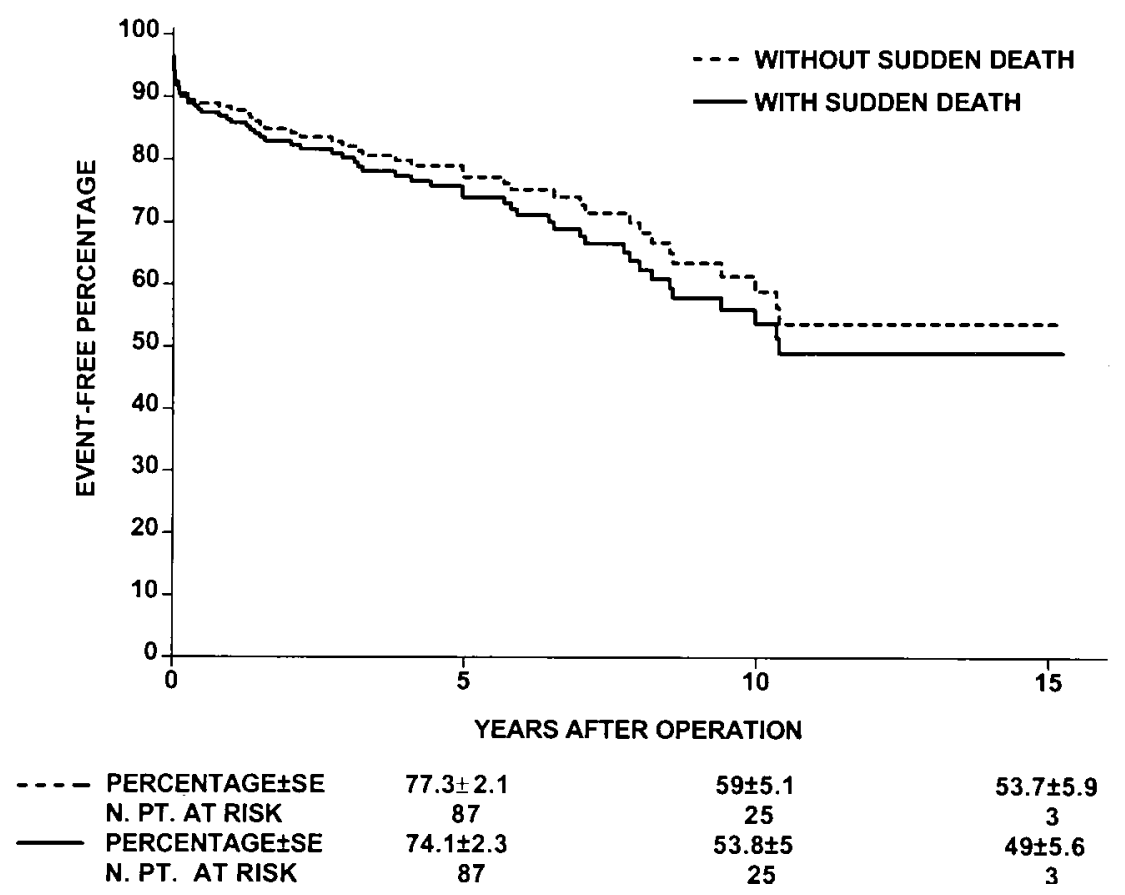

Fig. 6. Actuarial freedom from all valve-related events with sudden death being included or excluded from valve-related death. SE, Standard error of the estimate; N. PT., number of patients.

Table III. Ranges of linearized rates of valve-related events after double valve replacement with bileaflet prostheses (St. Jude Medical and CarboMedics) in 11 retrospective studies of the literature

\begin{tabular}{|c|c|c|c|c|c|c|c|c|c|}
\hline First author & Valve type & $\begin{array}{l}\text { No. of } \\
\text { patients }\end{array}$ & $\begin{array}{c}\text { Mean } \\
F U(y r)\end{array}$ & $\begin{array}{c}\text { Embolism } \\
(\% / p t-y r)\end{array}$ & $\begin{array}{l}\text { Bleeding } \\
(\% / p t-y r)\end{array}$ & $\begin{array}{c}\text { Valve } \\
\text { thrombosis } \\
(\% / p t-y r)\end{array}$ & $\begin{array}{c}\text { Endocarditis } \\
(\% / p t-y r)\end{array}$ & $\begin{array}{c}\text { Paravalvular leak } \\
(\% / p t-y r)\end{array}$ & $\begin{array}{l}\text { All valve-related } \\
\text { events }(\% / p t-y r)\end{array}$ \\
\hline Burckhardt $^{2}$ & SJM & 81 & 2.6 & 1.1 & - & - & - & - & - \\
\hline Kinsley $^{3}$ & SJM & 126 & 3 & 1.7 & - & 0.85 & 0.01 & - & 4.8 \\
\hline $\mathrm{Czer}^{4}$ & SJM & 74 & 3.3 & 2 & 3.1 & 0 & 0.3 & 0 & 6.1 \\
\hline Nakano $^{5}$ & SJM & 223 & $0.5-12$ & 0.79 & 0.1 & 0 & 0.2 & 0.2 & 1.28 \\
\hline Ibrahim $^{6}$ & SJM & 70 & 4.2 & 5 & 2.1 & 0.001 & 1 & 1.26 & - \\
\hline Baudet $^{7}$ & SJM & 132 & 9.7 & 1.6 & 1.01 & 0.7 & 0.3 & 0.1 & 3.74 \\
\hline Smith $^{8}$ & SJM & 64 & 5 & 0.3 & 0.3 & 0 & 0.3 & 0.3 & - \\
\hline de Luca ${ }^{9}$ & CarboMed & 76 & 1.5 & 0.3 & 0.65 & - & - & - & - \\
\hline Armenti $^{10}$ & SJM & 92 & 2.8 & 4.6 & 1.2 & 0 & 2.5 & - & 9.1 \\
\hline Arom $^{11}$ & SJM & 100 & 5 & 1.29 & 0 & 0.32 & 0 & 0.32 & - \\
\hline Copeland $^{29}$ & CarboMed & 144 & 2.5 & 3.1 & 1.24 & 0 & 1.55 & 1.24 & - \\
\hline
\end{tabular}

CarboMed, CarboMedics valve; Mean FU (yr), mean time of follow-up in years, except for the study of Nakano and associates, in which only the range was mentioned; SJM, St. Jude Medical valve.

than $50 \%$, age older than 70 years, and ventricular arrhythmias. Notably, the first two factors are also determinants of deaths of all causes. This is in keeping with coronary artery disease and coronary artery bypass grafting reported as the strongest predictor of valve-related mortality in the series of Czer, ${ }^{4}$ Ibrahim, ${ }^{6}$ and their associates, respectively. As with embolism, no valve-related factor is involved and even mitral valve repair has no bearing on valve-related outcome. Mitchell and colleagues ${ }^{24}$ clearly demonstrated that the valve-related complications were more importantly related to patientrelated factors, and Rahimtoola ${ }^{25}$ emphasized that "the results of valve surgery are dependent on many factors; the type of surgery or valve replacement device is only one variable that influences the results." Moreover, Stephenson and coworkers ${ }^{20}$ reported no influence of four different types of valve 
prostheses on the morbidity and mortality in combined aortic and mitral surgery, while in most patients late mortality and morbidity continued to be cardiac in nature or related to anticoagulant therapy.

A controversial point remains in the inclusion of sudden death in the valve-related deaths. The significant risk factors on univariate analysis were known preoperative ventricular arrhythmias and associated coronary artery disease. Although suggestive, univariate analysis does not prove a direct relationship between arrhythmias and sudden death. Here again, none of the valve-related factors have been identified as risk factors. This finding is in agreement with two recent autopsy studies questioning the value of classifying sudden death as valverelated death. Rooney and colleagues ${ }^{26}$ showed in 48 autopsies after sudden deaths with the Medtronic Hall valve (Medtronic, Inc., Minneapolis, Minn.) that $90 \%$ of deaths were unrelated to the prosthesis, and Burke and coworkers ${ }^{27}$ found among 37 patients with sudden death that more than half of the deaths were due to cardiac hypertrophy and atherosclerosis, hypothesizing a relationship with ventricular arrhythmia.

For survivors, the functional results were excellent, with most patients being in New York Heart Association class I or II at the time of follow-up. This confirms the functional improvement with mitral-aortic valve surgery to be more or less the same as with isolated valve surgery. Importantly, despite the overall good performance of bileaflet valves, the low incidence of freedom from all valve-related complications at 15 years $(49 \% \pm 5.6 \%)$ reminds us that patients who undergo prosthetic valve replacement do not have a normal outlook but have instead undergone substitution of one disease (prosthetic valve) for the original disease (native valve). However, when only valve-related complications with permanent impairment are considered, the freedom from such complications at 15 years is much higher $(79.3 \% \pm 6.7 \%)$.

Limitations of the study. The major limitation of the present study is that most information was collected retrospectively, a process that may reduce the validity of some data. However, particular attention was paid to the methods used in the follow-up. Information was collected twice for each patient. The general practitioner was interviewed, as well as the patient or his or her family. We used the personal interview, because its reliability has been shown to be superior to questionnaires sent by mail. ${ }^{28}$ In view of this and the high rate of follow-up, we still consider our data conclusive. Another limitation is the inclusion of patients with different types of mechanical valve prostheses. Nevertheless, all three types of valves used are bileaflet prostheses built on the same principle ${ }^{29}$; thus the incidence of valve-related events is likely not to be significantly altered by the type of prosthesis. This is supported by the findings of a recent prospective study comparing St. Jude Medical versus CarboMedics valves in mitral and multiple valve replacement operations: there were no distinguishing performance characteristics with regard to thromboembolic events. ${ }^{30}$ Moreover, in a study of our group, the ATS valve showed hemodynamic indices that were comparable with available results of other bileaflet and tiltingdisc prostheses. ${ }^{31}$ Risk factor analysis did not show valve type as a significant risk factor; thus the recruitment of consecutive patients appears to be more important than the recruitment of one type of valve. Clotting parameters at the time of embolic or bleeding events were unavailable in most patients. This lack is a major limitation in most studies of the literature. General practitioners should be encouraged to document the anticoagulation status at the time of any thromboembolic or bleeding event occurring in any patient after heart valve surgery, as well as on a regular basis during the follow-up.

REFERENCES

1. Akins CW. Results with mechanical cardiac valvular prostheses. Ann Thorac Surg 1995;60:1836-44.

2. Burckhardt D, Striebel D, Vogt S, et al. Heart valve replacement with St. Jude Medical valve prosthesis: long-term experience in 743 patients in Switzerland. Circulation 1988; 78(Suppl):I18-24.

3. Kinsley RH, Antunes MJ, Colsen PR. St. Jude Medical valve replacement: an evaluation of valve performance. $\mathbf{J}$ Thorac Cardiovasc Surg 1986;92:349-60.

4. Czer LSC, Chaux A, Matloff J, et al. Ten-year experience with the St. Jude Medical valve for primary valve replacement. J Thorac Cardiovasc Surg 1990;100:44-55.

5. Nakano K, Koyanagi H, Hashimoto A, et al. Twelve years' experience with the St. Jude Medical valve prosthesis. Ann Thorac Surg 1994;57:697-703.

6. Ibrahim M, O'Kane H, Cleland J, Gladstone D, Sarsam M, Patterson C. The St. Jude Medical prosthesis: a thirteen-year experience. J Thorac Cardiovasc Surg 1994;108:221-30.

7. Baudet EM, Puel V, McBride JT, et al. Long-term results of valve replacement with the St. Jude Medical prosthesis. J Thorac Cardiovasc Surg 1995;109:858-70.

8. Smith JA, Westlake GW, Mullerworth MH, Skillington PD, Tatoulis J. Excellent long-term results of cardiac valve replacement with the St. Jude Medical valve prosthesis. Circulation 1993;88(pt 2):49-54.

9. de Luca L, Vitale N, Giannolo B, Cafarella G, Piazza L, 
Cortrufo M. Mid-term follow-up after heart valve replacement with CarboMedics bileaflet prosthesis. J Thorac Cardiovasc Surg 1993;106:1158-65.

10. Armenti F, Stephenson LW, Edmunds LH. Simultaneous implantation of St. Jude Medical aortic and mitral prosthesis. J Thorac Cardiovasc Surg 1987;94:733-9.

11. Arom KV, Nicoloff DM, Kersten TE, Northrup WF, Lindsay WG, Emery RW. Ten-year follow-up study of patients who had double valve replacement with the St. Jude Medical prosthesis. J Thorac Cardiovasc Surg 1989;98:1008-16.

12. Fiore AC, Swartz MT, Sharp TG, et al. Double-valve replacement with Medtronic-Hall or St. Jude valve. Ann Thorac Surg 1995;59:1113-9.

13. Carpentier A. Cardiac valve surgery-"the French correction.” J Thorac Cardiovasc Surg 1983;886:323-7.

14. Edmunds LH Jr, Clark RE, Cohn LH, Miller DC, Weisel RD. Guidelines for reporting morbidity and mortality after cardiac valvular operations. J Thorac Cardiovasc Surg 1996; 112:708-11.

15. Butchart EG. The significance of sudden and unwitnessed death after heart valve replacement. J Heart Valve Dis 1994;2:1-4.

16. Nitter-Hauge S, Horstkotte D. Management of multivalvular heart disease. Eur Heart J 1987;8:643-6.

17. Horstkotte D, Schulte HD, Bircks W, Strauer B. Unexpected findings concerning thromboembolic complications and anticoagulation after complete 10 year follow up of patients with St. Jude Medical prosthesis. J Heart Valve Dis 1993;2:291-301.

18. Orsinelli DA, Becker RC, Cuénoud HF, Moran J. Mechanical failure of a St. Jude Medical prosthesis. Am J Cardiol 1991;67:906-8.

19. Lindblom D, Lindblom U, Aberg B. Long-term clinical results after combined aortic and mitral valve replacement. Eur J Cardiothorac Surg 1988;2:347-54.

20. Stephenson LW, Edie RN, Harken AH, Edmunds LH. Combined aortic and mitral valve replacement: changes in practice and prognosis. Circulation 1984;69:640-4.

21. Di Sesa VJ, Collins JJ Jr, Cohn LH. Hematological compli- cations with the St. Jude valve and reduced-dose Coumadin. Ann Thorac Surg 1989;48:280-3.

22. Horstkotte D, Schulte HD, Bircks W, Strauer B. Lower intensity anticoagulation therapy results in lower complication rates with the St. Jude Medical prosthesis. J Thorac Cardiovasc Surg 1994;107:1136-45.

23. Study Group of the Working Group on Valvular Heart Disease of the European Society of Cardiology. Guidelines for prevention of thromboembolisms in valvular heart disease. Eur Heart J 1995;16:1320-30.

24. Mitchell RS, Miller DC, Stinson EB, et al. Significant patientrelated determinants of prosthetic valve performance. J Thorac Cardiovasc Surg 1986;91:807-17.

25. Rahimtoola SH. Lessons learned about the determinants of the results of valve surgery. Circulation 1988;78:1503-7.

26. Rooney SJ, Moreno P. Lewis PA, Butchart EG. Sudden death in a large prosthetic valve series based on a single prosthesis: experience with the Medtronic Hall valve. J Heart Valve Dis 1993;3:5-9.

27. Burke PA, Farb A, Sessums L, Virmani R. Causes of sudden cardiac death in patients with replacement valves: an autopsy study. J Heart Valve Dis 1994;3:10-6.

28. Armstrong CS, Sun Z, David TE. Follow up of patients after valvular surgery: mail vs. telephone. J Heart Valve Dis 1995;4:346-9.

29. Copeland JG. An international experience with the CarboMedics prosthetic heart valve. J Heart Valve Dis 1995;4:5662.

30. Jamieson WRE, Miyagishima RT, Tyers FO, Lichtenstein SV, Munro AI, Burr LH. Bileaflet mechanical prostheses in mitral and multiple valve replacement surgery: influence of anticoagulant management on performance. Circulation 1997;96(Suppl):II134-40.

31. Karpuz H, Jeanrenaud X, Hurni M, et al. Doppler echocardiographic assessment of the new ATS medical prosthetic valve in the aortic position. Am J Card Imag 1996; 10:254-60. 
Appendix Table I. Variables $(n=39)$ screened by univariate analysis for mortality and complications

Variables

Categories

\begin{tabular}{|c|c|}
\hline \multicolumn{2}{|l|}{ Preoperative } \\
\hline Sex & Male/female \\
\hline Age (yr) & $\geq 70 /<70$ \\
\hline $\operatorname{BSA}\left(\mathrm{m}^{2}\right)$ & $\leq 1.7 />1.7$ \\
\hline Diabetes & Present/absent \\
\hline Hypertension & Present/absent \\
\hline COPD & Present/absent \\
\hline Angina pectoris & Present/absent \\
\hline Signs of $\mathrm{CHF}$ & Present/absent \\
\hline Peripheral vascular disease & Present/absent \\
\hline Prior myocardial infarction & Present/absent \\
\hline Prior cerebrovascular accident & Present/absent \\
\hline NYHA functional class & NYHA I-II/III-IV and I-III/IV \\
\hline $\mathrm{AF}$ & Present/absent \\
\hline Ventricular arrhythmias & Present/absent \\
\hline Creatinine $(\mu \mathrm{mol} / \mathrm{L})$ & $\geq 120 /<120$ \\
\hline Alcoholism & Present/absent \\
\hline Previous heart surgery & Present/absent \\
\hline $\mathrm{CT}$ ratio & $\geq 0.6 /<0.6$ \\
\hline ECG LVH & Present/absent \\
\hline Active endocarditis & Present/absent \\
\hline Surgical priority & Elective/urgent/emergency \\
\hline RAP (mm Hg) & $\geq 8 /<8$ \\
\hline PAPs (mm Hg) & $\geq 60 /<60$ \\
\hline PAPm (mm Hg) & $\geq 30 /<30$ \\
\hline PWCP (mm Hg) & $\geq 20 /<20$ \\
\hline LVDEP (mm Hg) & $\geq 10 /<10$ \\
\hline $\operatorname{LVDEVI~}\left(\mathrm{ml} / \mathrm{m}^{2}\right)$ & $\geq 100 /<100$ \\
\hline Cardiac index $\left(\mathrm{L} / \mathrm{m}^{2} / \mathrm{min}\right)$ & $\leq 2.5 />2.5$ \\
\hline LVEF $(\%)$ & $\leq 50 />50$ \\
\hline Physiopathologic anomaly & $\begin{array}{l}\text { Mitral regurgitation/mitral stenosis/mixed mitral disease/aortic regurgitation } \\
\text { aortic stenosis/mixed aortic disease }\end{array}$ \\
\hline Etiology of valve disease & Rheumatic/endocarditic/degenerative/congenital/previous prosthetic valve \\
\hline Associated tricuspid valvulopathy & Present/absent \\
\hline Associated CAD & Present/absent \\
\hline \multicolumn{2}{|l|}{ Operative and postoperative } \\
\hline Type of valve surgery & double heart valve replacement/mitral plasty and aortic valve replacement \\
\hline Type of valve prosthesis & St. Jude Medical/CarboMedics/Advance The Standing \\
\hline Aortic prosthetic size $(\mathrm{mm})$ & $\geq 23 /<23$ \\
\hline Mitral prosthetic size (mm) & $\geq 29 /<29$ \\
\hline Tricuspid valve operation & Present/absent \\
\hline Left auricular thrombectomy & Present/absent \\
\hline
\end{tabular}

After this first screening, we tested various combinations of aortic and mitral physiopathologic anomalies $(n=9)$ against the others. The same was done for the different causes of valve disease, different types of valve operations, and different types of valve prostheses. $A F$, Atrial fibrillation; $B S A$, body surface area; $C A D$, coronary artery disease; $C H F$, congestive heart failure; $C O P D$, chronic obstructive pulmonary disease; $C T$ ratio, cardiothoracic ratio on chest x-ray films; $E C G L V H$, ECG features of left ventricular hypertrophy; $L V D E P$, left ventricular end-diastolic pressure; $L V D E V I$, left ventricular end-diastolic volume index; $L V E F$, left ventricular ejection fraction; NYHA class, New York Heart Association class; $P A P m$, mean pulmonary artery pressure; $P A P s$, systolic pulmonary artery pressure; $P C W P$, pulmonary capillary wedge pressure; $R A P$, right atrial pressure. 